\title{
As Competências Soft nas Políticas Internacionais para a Educação Profissional e Tecnológica Pós-pandemia
}

\section{Soft Skills in International Policies for Post-pandemic Vocational and Technological Education}

Las Competencias Soft en Políticas Internacionales para la
Educación Profesional y Tecnológica Pospandémica

Emerson Freire ${ }^{1}$ Darlan Marcelo Delgado ${ }^{2}$ Sueli Soares dos Santos Batista ${ }^{3}$

RESUMO: A proposta deste artigo é estudar e colocar em debate, a partir de pesquisa bibliográfica e documental, se a noção de competências baseada em soft skills ainda seria capaz de enfrentar os desafios colocados após a crise de 2008 e, mais ainda atualmente, com a Covid-19, em um contexto de internacionalização da educação regida por diretrizes forjadas em agências multilaterais para uma formação que preconiza conhecimentos técnicos e tecnológicos sólidos, como a Educação Profissional e Tecnológica. O que se percebe é um crescente efeito colateral da aplicação dessa noção, uma fragilidade na formação por conhecimentos fortemente ancorados em conteúdos assentados nas ciências exatas como a matemática, a física, a química, a lógica, entre outras, e, menos ainda, em conteúdos de ciências humanas, como história, filosofia, sociologia, tão importantes quanto àqueles para a formação de uma cultura técnica, não tecnicista, como conceituada pelo filósofo francês Gilbert Simondon.

Palavras-chave: Educação Profissional e Tecnológica. Soft Skills. Internacionalização da educação. Cultura técnica.

ABSTRACT: Based on bibliographic and documentary research, this paper intends to study and debate whether the notion of competencies supported in soft skills would still be able to face the challenges posed after the 2008 crisis, even more, today with Covid -19. For this purpose, it also considers a context of internationalization of

\footnotetext{
${ }^{1}$ Centro Estadual de Educação Tecnológica Paula Souza. E-mail: freire.emerson@uol.com.br

${ }^{2}$ Centro Estadual de Educação Tecnológica Paula Souza (CEETEPS). E-mail: suelissbatista@uol.com.br

${ }^{3}$ Centro Estadual de Educação Tecnológica Paula Souza (CEETEPS) - Unidade de Pós-Graduação. E-mail: profdarlandelgado@gmail.com
} 
education governed by guidelines forged in multilateral agencies that advocates a solid technical and technological knowledge, such as Vocational and Technological Education. What is perceived is a growing side effect of the application of this notion, a weakness in the formation by knowledge strongly anchored in content based on the exact sciences such as mathematics, physics, chemistry, logic, among others, and, even less, in human science contents, such as history, philosophy, sociology. All of these considered important for, indeed, a solid formation of a technical culture, as conceptualized by the French philosopher Gilbert Simondon.

Keywords: Vocational and Technological Education. Soft Skills. Internationalization of education. Technical culture.

RESUMEN: La propuesta de este artículo es estudiar y debatir, a partir de la investigación bibliográfica y documental, si la noción de competencias basadas en soft skills podría seguir siendo capaz de afrontar los desafíos planteados tras la crisis de 2008 y, más aún hoy, con Covid-19, en un contexto de internacionalización de la educación regido por directrices forjadas en organismos multilaterales de formación que aboga por sólidos conocimientos técnicos y tecnológicos, como la Educación Profesional y Tecnológica. Lo que se percibe es un efecto colateral creciente de la aplicación de esta noción, una debilidad en la formación por conocimientos fuertemente anclados en contenidos basados en las ciencias exactas como la matemática, la física, la química, la lógica, entre otras y, menos aún, en contenidos de las ciencias humanas, como la historia, la filosofía, la sociología, tan importantes como los de la formación de una cultura técnica, no tecnicismo, tal como la conceptualizó el filósofo francés Gilbert Simondon.

Palabras clave: Educación Profesional y Tecnológica. Soft Skills. Internacionalización de la educación. Cultura técnica. 


\section{Introdução: a permanência da noção de competências na EPT em tempos de pandemia}

A noção de competências que vem sendo aplicada há anos nas organizações e que tem afetado diretamente o campo educacional, e em particular a Educação Profissional e Tecnológica (EPT), parece não só se manter viva como ter ganhado mais força em tempos de pandemia. Ao invés da busca por alternativas ao modelo de competências, que ajustou-se bem aos princípios neoliberais e ao regime de acumulação flexível, mas que tem mostrado suas deficiências desde a crise de 2008 e agora mais explicitamente diante da pandemia mundial da Covid-19, o que se percebe é o aprofundamento dessa noção, com sugestões de "novas" e sempre mais "novas competências" adaptativas para dar conta dos desdobramentos e consequências econômicas dessas crises, no mundo do trabalho e na configuração dos mercados, sem mesmo uma crítica sobre si, sem uma releitura sobre os limites do próprio modelo e suas implicações sociopolíticas.

A Educação Profissional e Tecnológica ${ }^{4}$ assumiu papel estratégico no cenário mundial desde as duas últimas décadas do século XX. Desde 1987, por exemplo, a Unesco atua para promover o ensino profissionalizante, quando a organização realizou o primeiro Congresso Internacional em Educação Profissional (Unesco, 1999). A ascensão do ensino profissionalizante em termos de sua relevância como instrumento de combate a diversos problemas econômicos e sociais - desemprego de jovens e adultos, trabalho informal, subemprego, falta de oportunidades, entre outras - coincide com os efeitos e as consequências de uma conjuntura de elementos determinantes de um novo contexto econômico, cultural, político e tecnológico.

Adiciona-se a este papel estratégico a inserção da EPT nos processos de internacionalização que a educação, de modo geral, vem experimentando desde os primeiros anos do século XXI. Tal dinâmica pode ser compreendida como resposta às demandas e exigências econômicas de um mundo intensamente globalizado (Batista, Freire \& Delgado, 2020).

A passagem do taylorismo-fordismo ao regime de acumulação flexível, como analisa Harvey (2013), está inserida no contexto de globalização, ou da transição entre duas formas de modernidade (e tipos de capitalismo), na análise de Bauman (1999, 2001), a saber, da(o) sólida(o) à(o) líquida(o). Harvey (2013) indica o ponto de inflexão no tempo: meados da década de 1970, época que também testemunhou o início do processo de desmonte do welfare state e das suas políticas de proteção social, com a transição das políticas econômicas keynesianas para as formas novo-clássicas, culminando

no

\footnotetext{
${ }^{4}$ Neste texto adota-se a nomenclatura "Educação Profissional e Tecnológica (EPT)". A Unesco adota a expressão Technical and Vocational Education and Training (TVET).
} 
neoliberalismo, a "nova razão do mundo" (Dardot \& Laval, 2016).

A conferir maior complexidade nesse cenário encontra-se a transição da tecnologia analógica para a digital e a revolução da microeletrônica. A esta se somam as revoluções da biotecnologia e da tecnologia dos materiais (Kon, 2016), o surgimento da Internet e das Tecnologias de Informação e Comunicação (TICs) e a inovação assumiu significativa centralidade - representando aplicações dos avanços em Ciência e Tecnologia (C\&T) - como mola propulsora de mudanças rápidas e da aceleração da competitividade econômica entre empresas (Delgado, 2015; Delgado \& Gomes, 2015).

Também é dos anos 1970 o primeiro modelo de gestão por competências, nos Estados Unidos, criado por David McClelland, o qual ainda estava ancorado no paradigma taylorista, baseando-se no tripé conhecimento, habilidades e atitudes (Dutra, 2017). Após este primeiro modelo, passa-se gradativamente a adotar a concepção da escola francesa de competências a qual, diferentemente da americana, as associa às realizações do indivíduo em determinado contexto laboral (Coda, 2016).

O surgimento da noção de competências está atrelado justamente às mudanças comentadas anteriormente e, conforme argumenta Dutra (2017), desde o início dos anos 1980 houve profundas transformações no cenário organizacional, em particular no que se refere a forma de gestão de pessoas.

A chamada pedagogia das competências, que tem em Perrenoud (1999, 2000, 2013) um célebre difusor, passou a ser adotada enfaticamente na Educação Profissional Tecnológica e difundida internacionalmente pela Unesco, em particular por meio do Projeto UNEVOC (Unesco, 1999), sendo elaborada a noção de educação baseada em competências (Bahl \& Dietzen, 2019).

Um documento publicado pela UnescoUnevoc (2020) referente ao "Dia das Habilidades dos Jovens" (World Youth Skills Day), celebrado todos os anos em 15 de julho, traz à tona as questões cruciais em meio à pandemia da Covid-19, seus impactos e as possíveis respostas ao cenário desafiador que se apresenta em termos do desemprego juvenil, do prejuízo causado ao relacionamento social entre os jovens, dado o necessário isolamento social, e das próprias transformações no mundo do trabalho. Como indica o documento, antes da crise pandêmica, os jovens com idade entre 15 e 24 anos já apresentavam duas ou três vezes mais chances de ficarem desempregados ou subempregados do que os adultos e um entre cada cinco nesta faixa etária estavam sem oportunidades de escolarização formal, emprego ou treinamento. Após o início da pandemia a situação se agravou e exacerbou as desigualdades em função das diferenças de acesso dos jovens às oportunidades de trabalho e aos recursos tecnológicos. Não por outro motivo, o documento que trata da conferência virtual ocorrida em julho de 2020 tem o título "Habilidades para uma juventude resiliente" (Unesco-Unevoc, 2020).

Conforme indica o documento, no mundo pós-COVID-19, assim que os jovens 
procurarem trabalho e forem chamados a contribuir para os esforços de retomada das atividades econômicas, eles necessitarão estar devidamente equipados com as competências para gerir de forma exitosa as mudanças emergentes e se adaptar para as futuras mudanças disruptivas.

Aliás, a palavra "disrupção" foi usada com ênfase por Jefferson Manhães, Reitor do Instituto Federal Fluminense (IFF), e outros expositores durante o webinário 5 "O Futuro da Educação Profissional"6, promovido pela Fundação Getúlio Vargas (FGV) em 06 de agosto de 2020. Segundo este gestor estaríamos diante da mais ampla disrupção da educação da história. No evento foi colocado que a educação profissional e tecnológica não só deve estar subordinada aos resultados de aprendizagem como também proporcionar a constituição de competências em uma trajetória de aprendizado contínuo - o conceito de lifelong learning - no contexto de fortes transformações.

No evento da FGV o professor Francisco Cordão afirma que as novas formas de organização e de gestão do trabalho apontam para alterações profundas no cenário pós-pandemia e de acelerado progresso tecnológico, o que exigirá formação profissional e cidadã baseada em múltiplas competências. A incerteza e a instabilidade econômica serão fatores prementes sobre os indivíduos e, portanto, sobre suas ações de busca por educação e formação profissional continuada. Devido a isso, os currículos da Educação
Profissional e Tecnológica precisam estar em fina sintonia com as demandas (e suas oscilações) do mundo do trabalho.

No entanto, é preciso entender melhor as concepções e as implicações da noção de competências e questionar se ainda ela é capaz de dar conta dos desafios e sequelas de um mundo pós-pandemia. O próprio ensino técnico e tecnológico sofreu nesse período, dado que 0 isolamento impossibilitou uma de suas maiores características que é contato direto com a materialidade da técnica e do fazer tecnológico em muitas áreas de formação. Estaria uma educação profissional e tecnológica ainda progressivamente moldada por competências socioemocionais, as chamadas soft skills, preparada para realizar seu tão propagado caráter estratégico para 0 mundo do trabalho?

Essa é uma questão que nos parece urgente e incontornável, para a qual não há respostas imediatas, mas que, no mínimo, precisa ser posta em debate, o que é a intenção principal deste artigo. Para tanto, o texto que se segue está dividido em mais quatro partes, além desta breve introdução.

Em um primeiro momento, o artigo retoma algumas concepções da noção de competências e seus desdobramentos, principalmente a partir da chamada escola francesa e dos estudos do sociólogo Philippe Zarifian (2003, 2012). A maior aceitação pelas organizações empresariais das ideias difundidas pela escola francesa,

\footnotetext{
${ }^{5}$ Aportuguesamento de "webinar" (web based seminar).

${ }^{6}$ Disponível em: <https://www.youtube.com/watch? $v=z x O 0$ cEoL404>. Acesso em 14 de agosto de 2020.
} 
em detrimento da escola americana, de certa forma consolidou e exacerbou as premissas contidas no conhecido Relatório Delors (1996), repetido exaustiva e, muitas vezes, acriticamente nos círculos escolares, ou ainda com inaudível resistência em função das políticas que Ihes são impostas, na busca por descobrir o tesouro da educação, como sugere o título do documento da Unesco assinado pelo economista e político francês Jacques Lucien Jean Delors. As competências socioemocionais, assim, se fortaleceram nos meios empresariais e acadêmicos tornando-se numa espécie de aposta para se alcançar a desejada conexão direta entre educação e o mundo produtivo. Essa problemática é desenvolvida na segunda parte do texto. O tesouro da educação a ser descoberto parece uma tentativa de restringir essa a uma prestadora de serviços eficaz e eficiente para as empresas dentro da lógica neoliberal, respondendo o mais velozmente possível, não tanto com conhecimento técnico somente, mas com habilidades comportamentais adaptativas, as soft skills. Essa aposta, já que não há estudos empíricos de longo alcance para demonstrar tal eficácia e eficiência para a formação dos indivíduos, nem mesmo para quem dela se beneficia, é possível ser verificada nas diretrizes das agências multilaterais dentro do contexto da internacionalização da educação e suas reverberações nas políticas públicas locais nacionais. A terceira parte deste artigo traz, então, essa discussão a partir de um exemplo de políticas atuais para a educação profissional e tecnológica no estado de São Paulo. A última seção procura pontuar algumas reflexões $e$ indagações finais, ancoradas em autores como David Harvey e Gilbert Simondon, considerando o contexto pós-pandemia que se apresenta e a formação técnica e tecnológica com suas especificidades.

\section{Concepções de competência e seus desdobramentos}

Etimologicamente, o termo competência pode ser buscado inicialmente nos termos em latim competere e competentǐa, significando capacidade de realizar uma tarefa ou função em conjunto, em competição (com: "junto" - petere: "disputar"). Resolver um problema, uma situação problemática, requer competência, mescla de habilidade e aplicação de conhecimento em um ambiente de discussão, de inquirição, de competição.

Embora relacionados, competência e habilidade têm conotações diferentes, conforme salienta Coda (2016). Habilidade é conseguir colocar em prática as teorias e os conceitos mentais que foram adquiridos. Competências é um termo mais amplo e consiste na reunião e combinação de conhecimentos, habilidades e atitudes (CHA), daí a necessidade do aprendizado constante e da participação da educação formal e informal nesse processo.

Há várias tipologias, dimensões e escolas das competências que vêm sendo desenvolvidas ao longo dos últimos trinta anos pelo menos, aprofundando essa 
racionalidade. Duas escolas, mais especificamente, interessam aqui por suas características e influências tanto no mundo da organização quanto em suas reverberações no âmbito educacional: as chamadas escola americana e escola francesa. Foge ao escopo desse estudo uma descrição histórica e detalhada dessas escolas. Basta, por hora, entender que a escola americana tem sua ênfase nos atributos e comportamentos do indivíduo que viabilizam sua atuação no trabalho, enquanto a escola francesa associa competências, independentemente de qualquer tipologia, necessariamente às realizações do indivíduo - frequentemente denominadas entregas - em determinado contexto, ou seja, àquilo que ele gera como resultado no trabalho. Em outras palavras, a diferença está em que a escola americana considera como competente alguém que possui uma característica que se acredita ligada a um desempenho de excelência, independentemente se esse indivíduo a utiliza ou não, ao passo que a escola francesa, considera competente alguém que demonstra aplicar essa característica, gerando um resultado desejado e observável. Esta última escola, cujos autores representativos são Zarifian (2012) e Le Bortef (2000), conseguiu uma aceitação nitidamente maior no atual contexto competitivo das organizações, até pela noção de característica subjacente explanada há pouco.

É porque desde o início dos anos 1980, conforme argumenta Dutra (2017), houve profundas transformações no cenário organizacional, inclusive no brasileiro, em particular no que se refere a forma de gestão de pessoas. $O$ autor indica três aspectos principais: i) a alteração no perfil exigido dos trabalhadores, passando-se de um perfil obediente e disciplinado para outro, autônomo e empreendedor; ii) deslocamento do foco do controle para o desenvolvimento das pessoas, indicando a passagem do paradigma taylorista ao regime flexível de acumulação; iii) a ênfase na relevância da atuação das pessoas como elemento para o sucesso da organização.

A base do conceito de competências da escola francesa é o deslocamento do foco sobre o estoque de conhecimentos $e$ habilidades do trabalhador para a forma como ele mobilizava tal estoque e repertório de saberes em contextos determinados. Nesse sentido, não apenas as competências em si como a própria gestão de pessoas deixam de centra-se nos cargos das organizações para focalizarem as pessoas.

Dutra (2017) comenta, a partir de Le Boterf $(1995,2000)$ que mais relevante do que o saber, o saber fazer ou mesmo o querer fazer, importa o saber ser. Esta forma de compreensão da construção das competências, da escola francesa, toma como significativa a perspectiva temporal de longo prazo, um processo perene de aprendizado e de mobilização de saberes contextualizados ao longo da vida. Isto é o que está nas origens das contemporâneas concepções de lifelong learning e de aprender a aprender como princípios pedagógicos.

Zarifian (2012) em seu livro "Objetivo Competência: por uma nova lógica" apresenta uma proposta de definição do 
conceito de competência que integra diversas dimensões e reúne várias formulações. Assim, primeiramente define competência como sendo "[...] 'o tomar iniciativa' e 'o assumir responsabilidade' do indivíduo diante de situações profissionais com as quais se depara" (Zarifian, 2012, p. 68 , grifos do autor).

A partir desta definição algumas considerações podem ser tecidas. Primeiramente tem-se que nessa formulação fica clara a mudança ocorrida na organização do trabalho, na medida em que se recua da prescrição e se abre espaço para a autonomia e automobilização do indivíduo, havendo com isso uma alteração também no que diz respeito ao envolvimento do indivíduo com o seu próprio trabalho. Também a questão da tomada de iniciativa deve ser destacada, dada a sua importância no cenário atual. De acordo com o autor o sentido profundo do "tomar iniciativa" encontra-se no fato de que o seu significado ilustra as capacidades do indivíduo como ser humano e não como um robô, as quais podem ser caracterizadas como, por exemplo, a modificação de algo já existente, a introdução de algo novo, a imaginação e a invenção.

Verifica-se ainda dentro desta primeira definição de competência apresentada por Zarifian (2012) a questão da responsabilização do indivíduo pelo seu trabalho, não sendo o mesmo visto como um simples seguidor de ordens, mas alguém que deve assumir a responsabilidade pela avaliação da situação, pela iniciativa que ela pode exigir e pelos efeitos que dela decorrem. Como afirma o referido autor, essa responsabilidade consiste na contrapartida da autonomia e da descentralização da tomada de decisão.

No que diz respeito ao comportamento do indivíduo em uma dada situação, por sua vez, tem-se que ele nunca é totalmente prescritível, visto que é parte intrínseca da própria situação. Assim, "[...] existe, na competência, uma parte que não será nunca apreensível com antecedência e, logo, que os referenciais não poderão nunca apreender inteiramente." (Zarifian, 2001, p.71). Complementarmente à primeira definição apresentada, Zarifian (2001, p.72, grifos do autor) apresenta então uma segunda abordagem para o conceito de competência: "A competência é um entendimento prático de situações que se apoia em conhecimentos adquiridos e os transforma na medida em que aumenta a diversidade das situações."

Como se pode notar, nesta segunda abordagem tem-se uma ênfase na dinâmica da aprendizagem, a qual é essencial no procedimento da competência. Os ciclos de aprendizagem devem ser compostos, assim, pela transformação de conhecimento e/ou geração de conhecimento novo a partir de observações, análises e compreensões acerca da realidade enfrentada, contemplando em alguns casos inclusive uma alteração nas estruturas e nos modelos mentais individuais.

A mobilização de conhecimentos em situações de trabalho, apontada por Zarifian (2012) como sendo essencial para o exercício da competência, também é contemplada em processos de aprendizagem, conforme aponta Nonaka 
(1997), na medida em que indivíduos nessas situações fazem uso tanto de conhecimentos tácitos, quanto explícitos, os quais, neste caso, devem ser utilizados de maneira reflexiva. Como ressalta Zarifian (2003), permanecer sempre aberto a contestações e a novas aprendizagens consiste em uma postura adequada e essencial para a manutenção da competência, de modo que a mesma não se torne simplesmente "pura rotina". No entanto, para que haja transformação e aumento na bagagem de conhecimentos do indivíduo é necessário que a situação por ele enfrentada tenha sido completamente explorada do ponto de vista do que é possível aprender com ela.

Nesse contexto também a formalização dos conhecimentos adquiridos pode exercer um importante papel, incentivando a compreensão das situações e, ao mesmo tempo, sistematizando e difundindo os novos conhecimentos delas oriundos. Tal formalização que tem sua relevância para o desenvolvimento de competências, é proposta por inúmeras teorias de aprendizagem organizacional, podendo-se destacar os trabalhos de Huber (1991) e Shrivastava (1983).

Ainda com respeito ao entendimento das situações, Zarifian (2012) aponta a necessidade de haver um equilíbrio entre o tempo e o aprofundamento indispensáveis para que se entenda plenamente uma situação, para que os novos conhecimentos e o confronto com novas situações sejam organizados de modo que o indivíduo evite os efeitos do embrutecimento e esteja aberto à aprendizagem do novo. De acordo com o autor, é importante destacar que esse equilíbrio não é unicamente pessoal, mas sim se caracteriza como um problema a ser abordado pela organização do trabalho.

Desse modo, Zarifian (2003, p.74, grifos do autor) apresenta complementarmente a seguinte definição: " $A$ competência é a faculdade de mobilizar redes de atores em torno das mesmas situações, é a faculdade de fazer com que esses atores compartilhem as implicações de suas ações, é fazê-los assumir áreas de coresponsabilidade". Com respeito a esta definição pode-se ponderar que qualquer situação um pouco mais complexa irá exceder as competências de um único indivíduo, demandando que o indivíduo, portanto, aprenda. Adicionalmente verificase a necessidade de uma comunicação e disponibilização das competências por todos os indivíduos envolvidos em uma situação em questão, o que, de acordo com Zarifian (2012), só irá acontecer caso os indivíduos experimentem o sentimento de participar das mesmas implicações da situação.

De acordo com Zarifian (2012) é a partir da combinação dessas três abordagens da competência por ele apresentadas, as quais são complementares, que se pode chegar a apreendê-la e, assim, mobilizá-la conscientemente.

No entanto, deve-se estar atento no referido contexto às implicações sociais e possíveis dificuldades resultantes da aplicação desse conceito de competência. A primeira delas diz respeito a uma mudança profunda do comportamento social dos trabalhadores, na medida em que ele passa a assumir responsabilidades, 
comprometendo-se, correndo riscos, tornando-se "[...] explicitamente devedor dos resultados de sua atividade" (Zarifian, 2012, p. 76, grifos do autor). A segunda, complementar à primeira, consiste no desenvolvimento de reflexão pelo trabalhador perante a sua própria atividade profissional, resultado da aceitação do indivíduo em assumir responsabilidades, o que implica em questionar seus métodos de trabalho e defrontar-se com problemas novos.

\section{A aposta nas soft skills}

Assertividade, atitude positiva, capacidade de ensinar e aprender, capacidades de liderança, criatividade, falar em público, poder de persuasão, saber trabalhar em equipe e outras habilidades desejáveis na formação dos estudantes já estavam presentes nos quatro pilares para a educação no século XXI, conforme preconizado pelo Relatório Delors (1996): aprender a conhecer, aprender a fazer, aprender a conviver e aprender a ser. Essas habilidades assim formuladas nos anos 1990 se encontram no espectro da mudança do fordismo para a acumulação flexível enquanto modo de produção, consumo e regulação das sociedades capitalistas.

Afinal qual é o tesouro a descobrir que o Relatório Delors anuncia e cujo anúncio ecoa mais fortemente passados mais de vinte anos? E tesouro para quem, quando conclama a todos a:

[...] não deixar por explorar nenhum dos talentos que constituem como que tesouros escondidos no interior de cada ser humano. Memória, raciocínio, imaginação, capacidades físicas, sentido estético, facilidade de comunicação com os outros, carisma natural para animador, ... e não pretendemos ser exaustivos. O que só vem confirmar a necessidade de cada um se conhecer e compreender melhor (Unesco, 1996, p. 20).

Não é ocioso demonstrar como essa formulação se insere na lógica do capital humano. Esse capital humano como um tesouro ainda não suficiente conhecido e explorado para um mundo essencialmente competitivo. Não basta descobrir e potencializar esse tesouro em cada estudante. É necessário que o estudante também se conscientize de que é seu dever conhecer e explorar ao máximo os talentos individuais para que se tenha um lugar no século XXI. Ele precisa fazer um constante e infindável investimento em si mesmo, com um ethos a ser seguido e com os riscos inerentes, como a lógica que impera no mercado financeiro, conforme demonstraram os estudos com executivos das transnacionais realizados por LópezRuiz (2007). Investir torna-se palavra corriqueira, presente no senso comum do cotidiano. Investe-se basicamente em tudo, na aprendizagem formal e informal, na carreira, na amizade e até mesmo nos relacionamentos íntimos, de modo que se possa crescer "como pessoa" e principalmente como "profissional", termos que se tornam quase sinônimos nesse ethos. 
Preparar para o trabalho como investimento estratégico de uma nação, ainda que isso não seja totalmente assumido como finalidade da educação, é algo já presente no relatório Delors (Unesco, 1996):

Além da aprendizagem de uma profissão, há que adquirir uma competência mais ampla, que prepare o indivíduo para enfrentar numerosas situações, muitas delas imprevisíveis, e que facilite o trabalho em equipe, dimensão atualmente muito negligenciada pelos métodos pedagógicos. Estas competências e qualificações tornamse, muitas vezes, mais acessíveis, se quem estuda tiver possibilidade de se pôr à prova e de se enriquecer, tomando parte em atividades profissionais e sociais, em paralelo com os estudos. Daqui a necessidade de atribuir cada vez maior importância às diferentes formas de alternância entre escola e trabalho (p. 20).

Caberá à escola, transformada em uma espécie de prestadora de serviços para as empresas, desenvolver nos estudantes como futuros trabalhadores, portanto, "as capacidades e disposições necessárias para competir de forma eficaz e eficiente" (Apple, 2004, p. 46).

Mais recentemente esse espectro novamente chega às reformas educacionais no Brasil no formato de competências socioemocionais destacadas na Lei 13415 de 2017 e na BNCC. As competências socioemocionais na BNCC são apresentadas dentro da proposta de desenvolvimento de competências gerais. Essas competências gerais se referem, nos termos do documento, como o esforço em mobilizar conhecimentos, habilidades, atitudes e valores na resolução das "[...] demandas complexas da vida cotidiana, do pleno exercício da cidadania e do mundo do trabalho" (p. 8).

A orientação é que todas as escolas brasileiras, a partir da BNCC, incorporem essas competências socioemocionais em seus currículos. A formulação do BNCC deixa clara a ligação dessa formulação com o que já se preconizava no Relatório Delors:

No novo cenário mundial, reconhecer-se em seu contexto histórico e cultural, comunicar-se, ser criativo, analítico-crítico, participativo, aberto ao novo, colaborativo, resiliente, produtivo e responsável requer muito mais do que 0 acúmulo de informações. Requer o desenvolvimento de competências para aprender a aprender, saber lidar com a informação cada vez mais disponível, atuar com discernimento e responsabilidade nos contextos das culturas digitais, aplicar conhecimentos para resolver problemas, ter autonomia para tomar decisões, ser proativo para identificar os dados de uma situação e buscar soluções, conviver e aprender com as diferenças e as diversidades (BNCC, 2019, p. 14, grifo nosso).

Destacamos na citação da BNCC as expressões "aprender a aprender" e "conviver e aprender com as diferenças e as diversidades" porque se referem aos mesmos termos do documento dos anos 1990, mas a formulação de uma forma geral se remete a esse aprender em todas as dimensões em que a subjetividade está no centro do desenvolvimento, devendo o estudante "reconhecer-se em seu contexto histórico e cultural, comunicar-se, ser criativo, analítico-crítico, participativo, 
aberto ao novo, colaborativo, resiliente, produtivo e responsável". O aprender a aprender seria a dimensão propriamente do conhecimento necessário para esse desenvolvimento $e$, nesse sentido, a tautologia se consolida.

Para o desenvolvimento das competências é necessário "muito mais do que acúmulo de informações". Faz-se necessário "saber lidar", "atuar com discernimento", "aplicar conhecimentos", "ter autonomia", "ser proativo" e "buscar soluções" numa dimensão essencialmente operativa, ou seja, unir os seus talentos à massa de talentos que fazem a engrenagem funcionar.

Essas competências reconhecidas e difundidas como soft skills são atributos essencialmente individuais, mas compreendem um harmônico e harmonizado conjunto de indivíduos adaptados e conformados por essas habilidades supostamente harmonizadoras. Caracterizam-se essas competências (e habilidades) por não serem específicas não só por abordarem dimensões éticas, afetivas e psicossociais. De fato, colocam-se em outro polo em que se situam as hard skills, aquelas habilidades de caráter técnico e essenciais para as peculiaridades dos diferentes postos de trabalho. Embora construída no argumento do aprofundamento acadêmico e a formação técnica profissional dos estudantes, a BNCC passa ao largo do que poderiam ser as hard skills em relação às soft skills quando se diferencia a preparação para profissões ou para ocupações.
Essa diferenciação é importante porque parece haver um afastamento da formação de especialistas técnicos propriamente ditos ou, pior, se está formando especialistas em comportamentos adequados somente. Antes de destacar que essa é uma forma de valorizar as escolhas dos estudantes e prepará-los para essas escolhas, políticas educacionais deveriam também se basear em estudos empíricos que demonstrassem a viabilidade dessas escolhas. Apple (2004), problematizando essa dimensão neoliberal que privilegia a escolha do consumidor-trabalhador, percebe que se deixam de lado questões fundamentais relacionadas ao mundo do trabalho: atividades e postos de trabalho desregulamentados, mal remunerados nos setores de serviço, demonstrando a tendência das relações entre capital e trabalho na lógica da informatização e informalização.

As competências socioemocionais, embora ressaltando as escolhas dos alunos que já as tem ou precisam ser preparados para tê-las, buscam enfatizar a dimensão ética, deixando a dimensão política em um lugar bastante problemático, numa proposta que se pensa construída a partir do protagonismo dos estudantes na sua vida pessoal e coletiva.

Se as competências socioemocionais são fundamentalmente individuais, centradas no sujeito, desenvolvedoras e reveladoras do seu protagonismo, cabe-nos questionar como esse protagonismo é entendido e qual a dimensão política presente nesse protagonismo. 
No documento em tela o protagonismo aparece associado à "autoria na vida pessoal e coletiva" (p. 9), "aprendizagem e construção de seu projeto de vida" (p. 14), "ampliação da autonomia". Há, nesse sentido, aspectos relacionados à criação $\mathrm{e}$ fruição estéticas, a saber:

[...] autoria nas práticas de diferentes linguagens; na identificação e na crítica aos diferentes usos das linguagens, explicitando seu poder no estabelecimento de relações; na apreciação e na participação em diversas manifestações artísticas e culturais e no uso criativo das diversas mídias (UNESCO, 1996, p. 470).

O protagonismo juvenil é defendido de maneira a associar-se a participação dos estudantes nos diversos segmentos da vida social e profissional, o que se pode configurar na maneira como a formação política é compreendida, sempre mediada pelas pautas de desenvolvimento socioeconômico ainda a serem problematizadas. Os conflitos são desafios a serem geridos por essa formação de pessoas razoáveis e bem adaptadas. Assim, a utopia do Relatório Delors é proclamada e reeditada em seguidas reformas educacionais supostamente inovadoras: "Nosso tesouro comum de sabedoria e de experiência pode levar-nos - e levará com certeza - a encontrar os meios de aumentar o nosso bem-estar espiritual e material e de vivermos juntos em harmonia" (UNESCO, 1996, p. 256).

\section{Das agências multilaterais às estratégias institucionais de internacionalização na EPT}

A ênfase nas competências gerais e mais recentemente nas competências socioemocionais é justificada em avaliações internacionais coordenadas pela Organização para a Cooperação e Desenvolvimento Econômico (OCDE) e pela Organização das Nações Unidas para a Educação, a Ciência e a Cultura (Unesco) que instituiu o Laboratório Latinoamericano de Avaliação da Qualidade da Educação para a América Latina. Esse é um pressuposto das políticas educacionais em nível internacional que passou pelo processo de formulação, podemos inferir, já nas discussões e elaborações que resultaram no Relatório Delors e se encontra agora em franco processo de implementação e de avaliação.
A Unesco-Unevoc indica logo no início de seu documento intitulado Work-based learning as a pathway to competencebased education (Bahl \& Dietzen, 2019) que o aprendizado baseado em problemas é reconhecido cada vez mais pelos Estados Membros como uma estratégia efetiva para promover a qualidade e a relevância da educação profissional, em especial, no que se refere ao seu potencial de preparar os jovens para o emprego e o trabalho. O horizonte em mira pela Unesco-Unevoc é o mundo do trabalho do amanhã, ou seja, do futuro que já se faz presente por meio do continuum fluxo tecnológico-econômico a descortinar uma trilha na qual a fluidez de todas as estruturas e dimensões permeadas e 
mediadas pela relação capital-trabalho é a marca emblemática. Cenário este resultante da transição da típica rigidez organizacional e da gerência do trabalho do padrão taylorista-fordista para o regime de acumulação flexível, como abordado por David Harvey na sua clássica obra Condição pós-moderna (Harvey, 2013).

Não são apenas as categorias capital e trabalho a serem revolucionadas a partir das consequências e desdobramentos do regime de acumulação flexível, da globalização e financeirização da economia e dos mercados. São todas as formas de interação e, inclusive, de comunicação tragadas para o interior de um turbilhão. O trabalho, como uma das formas de interação, e o capital, como forma social de produção e simultaneamente como estoque dos meios de produção, sempre foram categorias de análise caras à sociologia do trabalho $\mathrm{e}$ inclusivamente à sociologia da educação. Ambas foram submetidas a um estresse compreensivo originado pelas tensões e complexidades dos cenários produzidos na passagem da "solidez" do taylorismofordismo à "fluidez" do regime de acumulação flexível, para usar o vocabulário temático de Zygmunt Bauman em suas obras Modernidade líquida (Bauman, 2001) e Globalização (Bauman, 1999). A técnica, a ciência e a noção de inovação - comumente associada às duas primeiras - se apresentam como ingredientes a adensar a dinâmica de produção da existência material e do próprio estilo de vida social, colocando a constância do mundo industrial-fabril e a tradição dos costumes, da cultura e do trabalho na berlinda.

O empreendedorismo, abordagem calcada nas soft skills e nas noções de criatividade e inovação, é das principais vertentes da abordagem da pedagogia das competências, especialmente quando observadas as orientações da política internacional para a EPT preconizadas pela Unesco e Unevoc. O aprendizado ao longo da vida (lifelong learning), como necessidade de aprendizado perene, é outra dimensão de natureza comportamental que se espera dos jovens alunos da EPT.

No final do século passado, a Unesco já havia consolidado o projeto Unevoc (International Project on Technical and Vocational Education ), o qual teve início em 1991, totalizando 200 Centros Unevoc em 130 países. O documento gerado no Segundo Congresso Internacional em Educação Profissional, ocorrido em 1999 na Coreia do Sul, torna explícito o diagnóstico do momento e seus desdobramentos sobre a Educação Profissional:

É esperado que o novo século seja uma era de conhecimento, informação e comunicação. Os acelerados desenvolvimentos tecnológicos nos sistemas de produção requerem trabalhadores que possuam iniciativa e capacidade de atualizar suas competências. A globalização está obrigando os principais setores das economias nacionais a competir em cenários de acelerada mudança e a

\footnotetext{
${ }^{7}$ Projeto Internacional para a Educação Profissional (tradução livre).
} 
alcançar padrões internacionais de qualidade e produtividade. Cada país será, desse modo, obrigado a disponibilizar aos seus cidadãos a possibilidade de adquirirem a educação e as competências necessárias para sobreviver e melhorar sua qualidade de vida. No mundo de amanhã todo indivíduo precisará atualizar seus conhecimentos e competências constantemente (Unesco, 1999, p. 2, tradução livre).

Como se pode verificar, os principais elementos a se destacar são: i) conhecimento, informação e comunicação; ii) acelerada mudança tecnológica; iii) iniciativa e capacidade em atualizar competências; iv) competir em cenários em mudança acelerada; v) alcançar padrões internacionais de qualidade e produtividade; vi) capacidade de atualização constante de conhecimentos e competências. As competências são consideradas chave para as economias do século $X X I$, imersas no novo cenário competitivo e pautado em inovações (Unesco, 2015a).

Mais recentemente, a reforma do ensino médio no Brasil iniciada por meio da Lei 13.415 de 2017, enfatiza a formação técnica e profissional como um dos itinerários formativos para o desenvolvimento nos aspectos físicos, cognitivos e socioemocionais dos secundaristas. A profissionalização, como parte do projeto de vida do aluno, é defendida em contextos extramuros da EPT num novo formato para uma educação integral. Isso nos neva a refletir sobre a observação de Akkari (2013) de que já não se pode falar de políticas educacionais nacionais que não estejam entranhadas nas diretrizes internacionais e internacionalizantes.

A BNCC é um documento bastante extenso e intensamente lido e discutido em estudos demonstrando o seu alcance e os seus limites na reformulação do ensino médio, especialmente quanto ao que se refere à EPT enquanto itinerário formativo e que segue os mesmos preceitos internacionais.

Se tomarmos como exemplo uma importante instituição de ensino técnico e tecnológico do estado de São Paulo, o Centro Estadual de Educação Tecnológica Paula Souza (Ceeteps), é possível, se não generalizar, tentar observar a dimensão com que as diretrizes das agências multilateriais acabam por influenciar as políticas de internacionalização, sempre sob a batuta da noção de competências atrelada à perspectiva neoliberal de formação.

O Ceeteps, já em 2019, construiu um documento designado "Rol de competências socioemocionais". Esse documento, como o nome já indica, é uma lista organizada para relacionar itens de três dimensões interligadas: o perfil de competências socioecomocionais, valores e atitudes relacionados com as competências socioemocionais e exemplos de componentes curriculares direcionados ao desenvolvimento de competências socioemocionais (Ceeteps, 2019). Esse documento teve como base normatizações nacionais e internacionais e se destaca um estudo divulgado por Vargas (2014), vinculado ao Cinterfor (OIT), em um evento chamado Jornada Catarinense da Indústria, organizado pela 
Federação das Indústrias do Estado de Santa Catarina (FIESC).

Fernando Vargas é especialista Senior de OIT/Cinterfor no âmbito da EPT, tendo experiência em organização de sistemas e instituições educacionais, de processos de identificação e de demandas, bem como estruturação de programas, execução, certificação e evolução da formação.

No estudo que apresentou no evento em Santa Catarina e que serve como um dos referenciais do documento produzido pelo Ceeteps, enfatiza que o capital humano de uma nação, ou seja, "as habilidades e as capacidades que residem nas pessoas e seu uso produtivo" pode ser o determinante mais importante de seu êxito econômico comparado a outros recursos, sendo que o índice de capita humano "mede a capacidade dos países de desenvolver e produzir trabalhadores sãos" (Vargas, 2014, p. 4).

É interessante que o documento em tela não cite a BNCC, embora seu escopo e consequências de sua implementação se configurem com uma espécie de laboratório para essa política educacional. Assim é que o Ceeteps em 2019 estabeleceu uma parceria com a American College Testing (ACT). A partir da parceria com essa instituição americana foi possível realizar testes com alunos de ETECs e FATECS para medir suas competências sócioecomocionais.O objetivo foi de identificar perfis profissionais e avaliação de competências com foco nos aspectos cognitivos e comportamentais desses estudantes. A ACT foi validada pelo Ceeteps por ser "conhecida mundialmente" e "por promover testes utilizados por universidades norteamericanas para a seleção de candidatos" (Ceeteps, 2020).

Faz parte da parceria o uso dos resultados dos testes para que se possa, a partir deles, avaliar ações administrativas e pedagógicas que visem melhorar os pressupostos e práticas dos Projetos Políticos Pedagógicos das unidades de ensino, bem como seus planos de curso a partir de reogarnização curricular (Nascimento, 2020).

Segundo relatório das ações governamentais voltadas para a EPT em São Paulo, publicado no Diário Oficial em 16 de maio de 2020, foram aplicados pela ACT os testes Tessera (para soft skills) e WorkKeys (para hard skills), gratuitamente, em 3.000 alunos formandos de Etecs e Fatecs. Esses dados se encontram em espaço destinados às ações de internacionalização do Ceeteps com ênfase em mobilidade acadêmica, talvez pressupondo-se que entre esses egressos avaliados haja uma parte com capacidade para estudar ou trabalhar em instituições americanas e de outros países. $\mathrm{Na}$ divulgação do teste entre os alunos do Ceeteps foi ressaltado que a sua gratuidade se devia à parceria, quando em outras situações a realização do teste tem um custo de 400 reais. Foi divulgada a informação de que a certificação da ACT se tornou amplamente utilizada para contratação de profissionais por empresas dos Estados Unidos, também sendo aceita em países como México, Chile e Honduras.

A oferta do teste foi divulgada amplamente nos sites das Etecs e das Fatecs com os 
argumentos de que "por meio de metodologia avançada, os testes proporcionam resultados precisos, com emissão de relatórios com feedback para apoiar o autoconhecimento, crescimento e a melhoria contínua da formação do discente", sendo a ACT uma organização que é responsável pelo teste Pisa "oferece às pessoas um conjunto de soluções exclusivamente integradas, projetadas para fornecer insights personalizados ao longo da vida" (Fatec Sorocaba, 2020).
Com esse exemplo, é possível observar mais proximamente como diretrizes internacionais, com noções confeccionadas a partir de outras realidades e experiências terminam por influenciar nas políticas nacionais de educação, em um embate que se torna geopolítico em última instância, e que que na ponta ressoam no ambiente escolar que, muitas vezes, replicam tais noções, adaptando-as à dinâmica local ou, por vezes, resistem com vozes surdas ante à letra das leis sancionadas.

\section{Algumas reflexões e indagações finais}

Do fordismo à acumulação flexível, como se viu, não temos apenas formas de controle macroeconômico, mas a construção de modos de vida totalizantes. Para Harvey (2013), as consequências ideológicas e políticas da superacentuação da flexibilidade exigem avaliações do caráter imperativo da destruição e reconstrução acelerada das habilidades dos trabalhadores como uma característica central da passagem do fordismo para os modos flexíveis de acumulação.

É de dentro deste contexto de ruptura econômica, organizacional e tecnológica, cujo ponto de inflexão se deu nos anos 1970, conforme discute Harvey (2013), que emerge a noção de educação por competências, assumindo a posição outrora celebrada no taylorismo-fordismo do conceito de qualificação. Pode-se afirmar que a educação por competências surge no processo de intensificação dos processos de trabalho e consequente aceleração na desqualificação e requalificação, exigindo a formação continuada para os trabalhadores.

Conforme explica Helena Hirata em texto significativo da década de 1990,

A competência é uma noção oriunda do discurso empresarial nos últimos dez anos e retomada em seguida por economistas e sociólogos na França (cf. M. Dadoy, 1990). Noção ainda bastante imprecisa, se comparada ao conceito de qualificação, um dos conceitos-chaves da sociologia do trabalho francesa desde os seus primórdios (cf. P. Naville, 1956); noção marcada política e ideologicamente por sua origem, e da qual está totalmente ausente a ideia de relação social, que define o conceito de qualificação para alguns autores (cf. D. Kergoat, 1982, 1984; M. Freyssenet, 1977, 1992) (Hirata, 1998, p. 132).

A centralidade que passou a assumir a noção de competência, a partir deste momento histórico recente, está inscrita no contexto de uma "reestruturação geral de 
toda a sociedade", como analisa Silva (2008). Dito de outra forma, não se trataria apenas de uma reestruturação produtiva, assim como não seria preciso afirmar ocorrer tão somente uma adequação ou adaptação da formação educacional e profissional dos trabalhadores às novas necessidades de trabalho oriundas das transformações econômicas, tecnológicas e organizacionais. Seria, efetivamente, uma mudança paradigmática a colocar em cena um novo capitalismo ou uma nova economia e convulsionar as possíveis capacidades explicativas das categorias capital e trabalho.

Segundo Coda (2016, p. 4, destaques do original) ${ }^{8}$, uma clássica definição de competência pode ser assim expressa

"Uma competência é uma característica subjacente a um indivíduo que tem uma relação causal com algum critério considerado como referência ou com um desempenho superior em um cargo ou situação".

Característica subjacente significa que uma competência é uma parte profunda e durável da personalidade de um indivíduo e que pode prever seu comportamento em uma ampla variedade de situações e atividades de um cargo.

Não por acaso, os estudos da administração, principalmente os psicossociais provenientes dos setores de $\mathrm{RH}$, encontraram no conceito de competência um rico arsenal para vincular o comportamento das organizações ao comportamento das pessoas, transferindo a competição entre as instituições econômicas, principalmente no contexto de globalização e mundialização do capital financeiro, para o indivíduo. É o que se entende por alinhamento no jargão corporativo, uma correlação imediata, com todas suas implicações benéficas $e$ perversas, entre as competências organizacionais e pessoais, tornando o objetivo da empresa o mesmo do indivíduo que realiza seu trabalho diário, inclusive para seu "crescimento pessoal", como reconhece Coda (2016, p. xiii):

Os tempos atuais solidificam a globalização e juntamente com esse processo a necessidade imperativa das organizações em buscar competitividade e excelentes resultados operacionais. [...] o conhecimento sobre como as pessoas agem durante 0 exercício de suas atividades e cargos vem se tornando um tema crítico e merecedor de atenção, a fim de auxiliar na obtenção de vantagens competitivas que, por um lado, melhoram o desempenho empresarial e, por outro, possibilitam garantir oportunidades de crescimento profissional e de realização para os colaboradores.

O "colaborador" se realiza pessoal e profissionalmente somente melhorando seu desempenho, investindo ao longo de sua vida em competências que estão alinhadas aos objetivos que não são necessariamente seus, mas os da empresa, ou de uma espécie de ser-empresa que passa a carregar consigo, nas mínimas atitudes comportamentais, isto é, as suas "características subjacentes". Uma gestão política do ser, uma questão ontológica, em que se entra no íntimo da vida cotidiana das

${ }^{8}$ Conforme argumenta Coda (2016) esta definição foi proposta na obra Competence at work, de L.M. Spencer Jr. e S.M. Spencer (1993) e é inspirada pelas contribuições de David McClelland. 
pessoas, em que há a introjeção no corpo/mente do indivíduo das competências organizacionais, da lógica da empresa, como valores invioláveis para o "sucesso" individual, para a "felicidade", para o "crescimento profissional", ao mesmo tempo que servem para o controle de população, para o regramento social.

É nesse ponto que a noção de competências encontra parceria ideal no modelo neoliberal, não como ideologia ou política econômica, como lembram Dardot e Laval (2016), mas como fundamentalmente uma racionalidade que, como tal,

tende a estruturar e organizar não apenas a ação dos governantes, mas até a própria conduta dos governados. A racionalidade neoliberal tem como característica principal a generalização da concorrência como norma de conduta e da empresa como modelo de subjetivação (p. 17).

Por um lado, observa-se uma problemática que atinge a formação sociopolítica do indivíduo, em que a democracia de um conceito essencialmente político se torna restritamente econômico, mercadológico. $\mathrm{O}$ estudante bem desenvolvido em suas competências socioemocionais é aquele que bem incorporou o sujeito empresarial. É essa ética que importa, com seus valores de empreendedorismo e capital humano (in)corporados, sem que haja possibilidades de questionamentos políticos mais agudos. Consideramos que essas reformas educacionais em curso se inserem numa lógica neoliberal $e$ neoconservadora própria da acumulação flexível como modelo de organização e regulação socioeconômica. Nessa lógica, "todas as pessoas devem agir de maneira que maximizem seus benefícios pessoais" (Apple, 2004, p. 46), o que significa, pela lógica do alinhamento, maximizar a produtividade da empresa, principalmente se consideramos 0 contexto de precarização do trabalho e de escassez de empregos formais. Aos que ainda se mantém no mundo do trabalho, investindose constantemente, resta a intensificação das atividades em busca de atingir as metas de produtividade sempre mais altas que se impõem em nome da competitividade.

Por outro lado, inclinando-se para a formação técnica e tecnológica, uma segunda problemática se apresenta concomitante e complementar àquela anterior.

Aqui, a noção de educação por competências ganhou ênfase em consonância com a própria dinâmica de assunção da Educação Profissional e Tecnológica (EPT) como política educacional estratégica pelas organizações internacionais multilaterais, com destaque para a Unesco-Unevoc. As competências profissionais, atitudinais e comportamentais passam a se consolidar como marcas emblemáticas da concepção de educação e formação profissional como instrumentos pedagógicos, no interior da EPT, para combater $\mathrm{o}$ desemprego de jovens $\mathrm{e}$ adultos, a informalidade laboral, o subemprego, a exclusão de oportunidades de recolocação no mundo do trabalho, o desemprego tecnológico, entre outras situações desafiadoras aos policy makers.

Ao mesmo tempo que as soft skills podem ser portadoras do potencial de proporcionar 
inserção no emprego contemporâneo e suas exigências, aumentar a probabilidade de permanência na formalidade e produzir habilidades para as pessoas aproveitarem situações de trabalho e geração de renda, mas não associadas necessariamente ao emprego registrado (formal), por outro lado, elas parecem se afastar de uma sólida formação educacional propriamente técnica e tecnológica. Em outras palavras, as políticas que focalizam a oferta de formação privilegiando competências atitudinais, comportamentais e socioemocionais, consideradas necessárias e úteis aos novos padrões dessa nova economia, podem produzir, como efeito colateral, uma fragilidade na formação de conhecimentos fortemente ancorados em conteúdos assentados nas ciências exatas como a matemática, a física, a química, a lógica, entre outras, e, menos ainda, em conteúdos de ciências humanas, como história, filosofia, sociologia, tão importantes quanto àqueles para a formação de uma cultura técnica, de fato, como a reclamada pelo filósofo francês, Gilbert Simondon (1969), em que se explore as potencialidades mais amplas da relação homem-tecnologia e não apenas contemple perspectivas redutoras dessa relação, via de regra guiadas unilateralmente por abordagens tecnicistas e mercadológicas. Por isso pensar a especificidade da formação técnica e tecnológica é fundamental, incluindo o próprio entendimento tecnologia na criação de redes sociotécnicas.

Simondon (1989, p. 263) nos lembra que há um hábito em se tratar os técnicos, ou tecnólogos, como trabalhadores especializados, o que seria um equívoco grande. Os trabalhadores especialistas, ainda mais se forem, principalmente como agora, especialistas em comportamentos (soft skills) adaptativos, não são verdadeiros técnicos, mesmo que tenham alguma base de técnica aprendida durante a formação. O técnico, no sentido amplo que Ihe dá Simondon, é aquele que é o mediador entre a comunidade e o potencial escondido e inacessível do objeto técnico, aquele que conhece a tecnicidade contida no modo de existência dos objetos técnicos, que the dá sentido, de quem se exige esforço constante de pesquisa tecnocientífica e cultural para estabelecer uma relação do objeto com o social, por meio da invenção e não somente da inovação subordinada aos interesses mercadológicos apenas. Todo espetáculo técnico é pueril e esconde a potencialidade da relação homem-técnica-sociedade, já sentenciava Simondon. E colocar o técnico como simples especialista de espetáculos é empobrecer seu papel mais agudo na orquestração entre os conjuntos técnicos e a cultura.

A atividade técnica inventiva pode ser considerada como promissora às realidades sociais, na visão de Simondon, uma vez que introduz a possibilidade de liberdade do indivíduo, de emancipação, para usar outro termo. Trata-se efetivamente de incorporar a técnica à cultura, uma tecnocultura que se afaste do uso instrumental da técnica e da tecnologia. É nesse sentido que Simondon propõe uma espécie de reconciliação entre cultura e técnica por intermédio da formação de uma "cultura técnica", que possibilite uma 
"tomada de consciência do sentido dos objetos técnicos" (1969. p. 9). Diferente do que se possa imaginar em um primeiro momento, favorecer uma "cultura técnica" é - contrário do estabelecimento do "tecnicismo intemperante", nas palavras do filósofo, o que significaria apenas uma "idolatria da máquina", fortalecida por "uma formação empobrecida voltada à especialização e moldada pela predominância de um único sentido, o econômico, desfavorecendo a invenção como parte constitutiva do fazer técnico em sua relação com o homem e o mundo" (Freire, 2018, p. 22). Uma formação exclusivamente especializada tecnicamente, reduz o entendimento mais abrangente sobre técnica e tecnologia, pois acaba centrando-se em fatores externos aos objetos técnicos, ou seja, em "relações com o público, forma particular de comércio" (Simondon, 1969, p. 13). Uma cultura técnica pretende dar um caráter realmente amplo à cultura por "reintroduzir nela a consciência da natureza das máquinas, de suas relações mútuas e de suas relações com o homem, e os valores implicados nessas relações" (p.13). Acrescente-se aí, inclusive, valores estéticos dessa relação, permitindo-nos assim conjeturar que essa formação sempre mais especializada, teria como reflexo uma lacuna que Simondon definiu em uma entrevista com a frase "faltam-nos poetas técnicos", ou seja, técnicos que tinham a capacidade de entender as afecções existente no processo inventivo comportando o tripé-homem-máquinasambiente (Freire, 2018).
E é interessante que Simondon considere que para essa introdução efetiva do objeto técnico na cultura, o tecnólogo é figura central, uma espécie de psicólogo ou de um sociólogo das máquinas, das tecnologias, que pode desvelar, considerando os esquemas de funcionamento, "a tecnicidade dos objetos, as possibilidades outras de relações do homem com o mundo. Mas, para tanto, um pensar mais abrangente e filosófico the é fundamental" (Doti \& Freire, 2020, p. 410).

Ou seja, um técnico ou tecnólogo que tenha sua formação calcada principalmente em competências comportamentais, devidamente já regradas às normas empresariais, com sua ética e racionalidade pré-estabelecidas, dificilmente poderá estabelecer conexões mais amplas com outros setores da sociedade, uma vez que suas competências estão pré-moldadas para um único setor dessa sociedade, o empresarial.

É um paradoxo que surge dessa dupla problemática exposta, que de um lado comporta uma formação distanciada da política, seguindo uma única valoração possível, a da empresa neoliberal e, por outro lado, a frágil formação técnica e tecnológica estrita, já que abre espaços constantes justamente para essa valoração ubíqua por competências dirigidas aos comportamentos aceitáveis e adaptativos. Um paradoxo que, ao pensar a invenção como motor do desenvolvimento humano, restringe-se ao instrumentalismo do velho progresso técnico, sem possibilidades de aliar as dimensões técnicas às políticosociais ou, nos termos de Simondon, 
conectar as intuições político-sociais às intuições técnicas-tecnológicas:

Ora, pode haver relação complementar entre as intuições de integração aos conjuntos técnicos e as intuições político-sociais, porque as intuições técnicas exprimem o resultado da história e do condicionamento da vida, do hic et nunc, enquanto as intuições político-sociais são projeto em direção ao futuro, a expressão ativa de potenciais (Simondon, 1969, p. 229, tradução livre nossa)

O que se percebe é que essas duas intuições, as técnicas e as político-sociais, não se conversam há tempos, parecem distantes, ou, sendo mais rudes e diretos um pouco, fracassaram, e que, mesmo assim, não se questiona o casamento entre a formação, aparentemente mais humanizada por meio das competências comportamentais e seus estreitos laços com a racionalidade neoliberal, o que nos parece um questionamento urgente a se fazer, seja dentro do campo da EPT, mais especificamente, como do educacional lato sensu.
Uma questão que os propagadores desse casamento necessitariam responder com estudos e reflexões efetivos de longo alcance, para além do discurso vigente desde antes do Relatório Delors (1996), ao invés de seguir na criação de "novas" competências a serem seguidas ad nauseam pós-pandemia, como se tem lido e visto, principalmente acriticamente em países como o nosso, mantendo a mesma lógica arquitetada desde 0 ponto de inflexão surgido nos anos 1970. Há que se inquerir fortemente, então, se essa aposta nas soft skills, em um contexto internacional pós-pandêmico que se apresenta, ainda deveria ser realmente levada adiante, mesmo tendo mostrado fragilidades, pelo menos desde a crise de 2008 e arrefecida agora com a Covid-19, em apresentar resultados consistentes em um ambiente de ensino que preconiza uma formação com conhecimentos técnicos e tecnológicos sólidos, como a EPT.

Recebido em 18 de novembro de 2020 Aprovado em 30 de abril de 2021 
Akkari, A. (2011). Internacionalização das políticas educacionais. Rio de Janeiro: Vozes.

Apple, M. (2004). Entre o neoliberalismo e o neoconservadorismo: educação e conservadorismo em um contexto global. In: BURBULES, Nicholas C.; TORRES, C. A. Globalização e educação: perspectivas críticas. Trad. Ronaldo Cataldo Costa. Porto Alegre: Artmed.

Bahl, A. \& Dietzen, A. (Eds.). (2019). Work-based learning as a pathway to competencebased education: a UNEVOC network contribution. UNEVOC: Bonn.

Batista, S., Freire, E. \& Delgado, D. (2020). Cursos superiores de tecnologia no contexto da internacionalização e da expansão da educação profissional e tecnológica no Estado de São Paulo. Série-Estudos, Campo Grande, MS, 25(54), 191-219. http://dx.doi.org/10.20435/serie-estudos.v25i54.1381.

Bauman, Z. (1999). Globalização: as consequências humanas. Rio de Janeiro-RJ: Zahar.

Bauman, Z. (2001). Modernidade líquida. Rio de Janeiro-RJ: Zahar.

Brasil. (2017) Lei de Diretrizes e Bases da Educação Nacional. Lei no 13.415/2017, de 13 de fevereiro de 2017. Recuperado de http://www.planalto.gov.br/ccivil_03/_ato20152018/2017/lei/L13415.htm. Acesso 01 mar 2020.

Centro Estadual de Educação Tecnológica Paula Souza. (2020). CPS avalia competências técnicas e socioemocionais de estudantes. Recuperado de https://www.cps.sp.gov.br/cps-avalia-competencias-tecnicas-e-socioemocionais-deestudantes/. Acesso 18 jul 2020.

Centro Estadual de Educação Tecnológica Paula Souza. (2019) Rol de competências socioemocionais.

Recuperado de http://cpscetec.com.br/cpscetec/arquivos/2019/socioemocionais.pdf. Acesso 18 jul 2020.

Coda, R. (2016). Competências comportamentais: como mapear e desenvolver competências pessoais no trabalho. São Paulo: Atlas.

Dardot, P. \& Laval, C. (2016). A Nova Razão do Mundo - Ensaio sobre a Sociedade Neoliberal. São Paulo: Editora Boitempo, 402 p.

Delgado, D. (2015). Inovação em educação na berlinda: da instrumentalização à emancipação. Linhas Críticas, Brasília, DF, 46, 764-783, set./dez. Recuperado de https://www.redalyc.org/articulo.oa?id=193543849011. Acesso 12 fev 2021.

Delgado, D. \& Gomes, L. R. (2015). Inovação em política e gestão da educação profissional e tecnológica: uma abordagem pela teoria crítica. São Paulo: Centro Paula Souza, 2015. 
Delors, J. \& Nanzaho, Z. (1996). Educação um tesouro a descobrir. Editora Cortez.

Doti, M. \& Freire, E. (2020). A urgência da filosofia em cursos superiores de tecnologia: para além da pragmática da eficiência e da normatividade. Revista de Filosofia Moderna e Contemporânea. 8(2), 405-418. http://doi.org/10.26512/rfmc.v8i2.27343.

Dutra, J. (2017). Competências: conceitos, instrumentos e experiências. 2 ed. São Paulo: Atlas.

Fatec Sorocaba. (2020). Testes Tessera e Workkeys para prováveis formandos. Recuperado de: http://www.fatecsorocaba.edu.br/noticia583.asp.

Freire, E. (2018). "Faltam-nos poetas técnicos": em direção a uma formação tecnoestética. In: Freire, E.; Verona, J. A.; Batista, S.S.S. Educação Profissional e Tecnológica: extensão e cultura. Jundiaí: Paco Editorial.

Harvey, D. (2013). Condição pós-moderna. 24 ed. São Paulo: Loyola, 2013.

Hirata, H. (1998). Da polarização das qualificações ao modelo da competência. In: FERRETTI, C. J. et al. (Orgs.). Tecnologias, trabalho e educação: um debate multidisciplinar. 4 ed. Petrópolis-RJ: Vozes.

Huber, G. (1991) Organizational Learning: the contributing process and the literatures. Organization Studies 17 (1): 49-81.

Kon, A. (2016) A economia do trabalho: qualificação e segmentação no Brasil. Rio de Janeiro: Alta Books.

Ministério da Educação. (2019) BNCC. Base Nacional Curricular Comum - BNCC (2019). Recuperado de: http://basenacionalcomum.mec.gov.br/images/historico/BNCC_EnsinoMedio_embaix a_site_110518.pdf.

Nascimento S.R. (2020) Empresa júnior no ensino técnico médio integrado: laboratório de aprendizagem para o desenvolvimento socioemocional, $161 \mathrm{f}$. Dissertação (Mestrado Profissional em Gestão e Desenvolvimento da Educação Profissional). Centro Estadual de Educação Tecnológica Paula Souza, São Paulo.

Nonaka, I. (1997). A empresa criadora de conhecimento. In: STARKEY, K. Como as organizações aprendem: relatos do sucesso das grandes empresas. São Paulo: Futura, 1997.

Sacristán, J., Gómez, A., Rodríguez, J., Santomé, J., Rasco, F., Méndez, J. ,..Pimenta, S. (2011). Educar por competências: o que há de novo? Porto Alegre: Artmed.

Shrivastava, P. (1983). A typology of organizational learning systems. Journal of Management Studies, 20 (1), 7-28.

Silva, M. (2008). Currículo e competências: a formação administrada. São Paulo: Cortez. 
Simondon, G. (1969). Du mode d'existence des objets techniques. Paris: Aubier - Montaigne.

Simondon, G. (1989) L'individuation psychique et collective: à la lumière des notions de forme, information, potentiel et métastabilité. Paris: Aubier.

United Nations Educational, Scientific, and Cultural Organizarion. (1999) Establishment of an international long-term programe for the development of technical and vocational education following the second international congress on technical and vocational education (Seoul, Republic of Korea, april 1999). Paris, 1999. Recuperado de: https://unesdoc.unesco.org/ark:/48223/pf0000117403.

United Nations Educational, Scientific, and Cultural Organization. (1996). Educação, um tesouro a Descobrir: Relatório para a UNESCO da Comissão Internacional sobre Educação para o século XXI. UNESCO/Edições ASA.

United Nations Educational, Scientific and Cultural Organization - International Centre for Technical and Vocational Education and Training. (2020). Virtual conference on skills for a resilient youth: virtual conference report. Bonn,. Recuperado de: https://unevoc.unesco.org/home/UNEVOC+Publications/lang=en/akt=detail/qs=6386

Vargas, F. (2014). Nuevas competencias para el profesional del siglo XXI. Jornada Catarinense da Indústria. Jornada Catarinense da Indústria. Recuperado de: http://santacatarinapelaeducacao.com.br/fmanager/senaimov/apresentacoes/arquivo 39_1.pdf

Zarifian P. (2012). Objetivo competência: por uma nova lógica. São Paulo: Atlas, 2012.

Zarifian P. (2003) O modelo da competência: trajetória histórica, desafios atuais e propostas. São Paulo: Editora Senac São Paulo. 